\title{
Child growth and development knowledge among senior nursing students
}

\author{
Azza H. Ahmed, Clara Richardson \\ School of Nursing, Collage of Health and Human Sciences, Purdue University, United States \\ Correspondence: Azza H. Ahmed. Address: 502 N University St. West Lafayette IN, USA. Telephone: 765-494-4040. \\ Email: ahmedah@purdue.edu. \\ Received: May 23, 2011 \\ DOI : $10.5430 /$ jnep.v3n1p82
}

\section{Abstract}

Background: Child and adolescents growth and development knowledge is an essential part of Pediatric Nursing and it is also part of the nine essentials in Nursing Education. Although students find challenge to master this knowledge, limited literatures documented the knowledge deficit regarding child growth and development among nursing students. The purpose of this study was to assess senior nursing students' knowledge about normal child growth and development before and after Pediatric Nursing didactic and clinical courses.

Methods: A prospective, descriptive, pre-post study was conducted using a convenience sample of 125 senior nursing students who were attending Pediatric Nursing courses during the academic year of 2010-2011. Students who attended and completed both didactic and clinical courses were eligible for the study. The students were given a questionnaire that was developed by the investigators at the beginning of the semester and at the end.

Results: Students' age ranged from 21 to 24 years old with mean 22.00 ( $\mathrm{SD}=0.8$ ). The mean knowledge score of the pre-test was 17.6 ( $\mathrm{SD}=3.29)$ (total is 28), while the mean knowledge score for the post-test was $19.00(\mathrm{SD}=2.76)$ at the end of the semester. Although there was a significant difference in the mean scores between the pre and post testing $(t=-3.04$, $p=0.003$ ), the students failed to achieve the $80 \%$ achievement rate in the post test.

Conclusions: Students had weak knowledge scores regarding main concepts of child growth and development after the Pediatrics Courses. Creative strategies that improve students' growth and development knowledge retention and demonstration are needed.

\section{Key words}

Child growth and development, Nursing students

\section{I ntroduction}

Knowledge of child development is the foundation upon which early childhood practice is based. Nurses should be aware of the psychomotor, socio-emotional, cognitive, and linguistic developmental domains in each stage of development and comprehend both the processes of development and their role in supporting each child's growth, development, and learning to be able to provide comprehensive and developmentally appropriate nursing care ${ }^{[1]}$. 


\section{Background}

Knowledge of normal childhood human growth and development is an essential part of nursing educations and part of the NCLEX-RN test plan ${ }^{[2]}$. The Essentials of Baccalaureate Education for Professional Nursing Practice developed by the American Association of Colleges of Nursing (AACN), the essentials sets the standard for baccalaureate curriculums across the country ${ }^{[3]}$. Threaded throughout this document is the concept of caring for individuals across the lifespan, which requires a well-grounded knowledge of human growth and development. Another important consideration in curriculum design is the Registered Nurse (RN) licensure examination. One of the underlying beliefs of this test plan is an understanding of the human condition across the lifespan, and question content specifies developmental stages and transitions. A pediatric nursing course addresses the early lifespan years from infancy through adolescence. Every topic covered in pediatric nursing is approached using a developmental framework. Wellness care, health promotion, acute care, chronic care, and end-of-life care are related to the child's developmental level. In addition, clinical experience involves developmentally adapted assessment, communication, safety measures, and patient care technology ${ }^{[1]}$.

Although several anecdotal and clinical education observations have noted that the knowledge and application of child growth and development is challenging for nursing students and new pediatric nurses, little literatures is available on students nurses knowledge of child growth and development. Literatures also documented that pediatric nurses had had knowledge deficits regarding principles of growth and development ${ }^{[4]}$ as well as primary care providers ${ }^{[5]}$. Extensive literature search revealed little evidence of empirical studies related to students' nurse and nurses' knowledge of growth and development. Studies that discussed nurses understanding of growth and development and child behavior were conducted many years ago (1980-1990). Recent studies presented creative ideas for teaching child growth and development ${ }^{[6,7]}$, however, no study tested students' knowledge about growth and development before they graduate and start their clinical career. The overall goal of this study is to evaluate the effectiveness of one program's efforts to prepare students to successfully pass the National Council Licensure Examination for Registered Nurses (NCLEX-RN) examination enabling them to practice as baccalaureate generalist nurses incorporating human growth and development into caring for young patients. Our purpose was to assess senior nursing students' knowledge about normal child growth and development before and after Pediatric nursing didactic and clinical courses.

\section{Methods}

\subsection{Design and sample}

A prospective, descriptive, pre/post study was conducted using a convenience sample of senior nursing students who were attending pediatric nursing courses during the academic year 2010-2011 from a Midwestern University. Students who attended and completed the didactic (3 credit hours) and clinical (2 credits hours) courses were eligible for the study. Students were excluded if they were taking either of the courses. A sample of 125 students completed the pretest and 123 students completed the posttest. Second-degree students were excluded from this sample because they were taking only the didactic course according to the school curriculum. Students had a previous required lifespan growth and development class during their sophomore year according to the curriculum.

\subsection{I nstrument}

A questionnaire was developed by the researcher based on the NCLEX-RN test plan requirements and the nine essentials in nursing education. The questionnaire composed of 28 multiple-choice questions and designed to measure students' knowledge of child development on two main theories of development beside physical development. The questionnaire included three main dimensions presenting Erikson Psychosocial, Piaget cognitive development theories and physical development focusing on the main developmental tasks for each stage of development as required by NCLEX-RN test plan. We considered content validity by panel of two pediatric nurses and two Pediatric nurse practitioners. The questionnaire ended with six questions about students' demographics and previous experience with growth and development 
making 34 questions. We checked the internal consistency for the questionnaire and the Cronbach's alpha was 0.54. A score of one was given to the correct answer and 0 for the wrong answer giving a total of 28 points with a range of scores from 0 to 28. The types of questions were mainly remembering and understanding level of learning based on new Bloom's revised taxonomy ${ }^{[8]}(90 \%)$ and application $(10 \%)$.

\subsection{Procedures}

Upon receiving the IRB approval from Purdue University, we gave the students paper and pencil questionnaires before the growth and development lectures in the beginning of the semester and one more time at the end of the semester after the students finished their theory lectures and clinical practice. Data collected during the academic semesters of Fall 2010 and Spring 2011. Participation in this study was voluntary. We invited all the students to participate in each semester and we received around $90 \%$ response rate from each group.

\subsection{Data analyses}

We used descriptive statistics such as percentage, mean, Stander deviation and standard error to describe students' demographics and knowledge. To compare the mean knowledge scores of the students' pre and post semester, we used one sample t-test to find the differences in the scores of pre and posttest. We set $80 \%$ as an achievement level for the pre/posttests since the students had life-span growth and development course during their sophomore year. Data analyzed using SPSS version $19^{\text {th }}$.

\section{Results}

\subsection{Participants}

The age of the students ranged from 21- 24 years old with a mean age of $22.00(\mathrm{SD}= \pm 0.8)(\mathrm{N}=125)$. Eighty five percent of the students were female. All the students had a previous course of lifespan growth and development. Majority of students (95\%) had previous experience with children such as working in camps, baby setting or working in clinical settings.

\subsection{Growth and development knowledge}

The mean knowledge score of pretest was 16.50 (3.07), while the mean knowledge score for posttest was 18.67 (2.54). The students' scores showed weak knowledge in the different dimensions of the growth and development. Table 1 describes the pre and posttests mean scores in the different dimensions of the questionnaire. Although there was a significant difference in the total mean knowledge scores between the pre and posttest $(t=6.07, p<.0001)$, the students failed to achieve the $80 \%$ achievement in each dimensions and in the total scores in the posttest (see Table 1). Findings from the posttest demonstrated knowledge deficits in most of the dimensions of the questionnaire. Table 2 presents selected items from the questionnaire and students responses.

Table 1. Difference between Pre Test and Post Test

\begin{tabular}{|c|c|c|c|c|c|c|}
\hline \multirow{2}{*}{ Questions } & \multicolumn{2}{|l|}{ Mean \pm SD } & \multicolumn{2}{|c|}{ Pre vs. Post } & \multicolumn{2}{|c|}{$80 \%$ achievement* } \\
\hline & Pre $(N=125)$ & Post $(\mathrm{N}=123)$ & $t$ & $P$ & $t$ & $P$ \\
\hline $\begin{array}{l}\text { Piaget Theory of Cognitive } \\
\text { Development }(0-12)\end{array}$ & $7.23 \pm 1.80$ & $7.88 \pm 1.67$ & 2.93 & .004 & -11.45 & $<.0001$ \\
\hline $\begin{array}{l}\text { Erickson Psychosocial } \\
\text { Development }(0-8)\end{array}$ & $4.58 \pm 1.09$ & $4.88 \pm 1.04$ & 2.23 & .027 & -7.72 & $<.0001$ \\
\hline Physical growth (0-8) & $4.69 \pm 1.25$ & $5.91 \pm 0.94$ & 8.68 & $<.0001$ & -5.77 & $<.0001$ \\
\hline Total (0-28) & $16.50 \pm 3.07$ & $18.67 \pm 2.54$ & 6.07 & $<.0001$ & -12.79 & $<.0001$ \\
\hline
\end{tabular}

*H0: The mean of posttest reaches at least $80 \%$ achievement 
Table 2. Students' pre and posttest responses to selected items of the questionnaire

\begin{tabular}{|c|c|c|c|c|}
\hline Criteria & $\begin{array}{l}\text { Pre-test } \\
(\mathrm{N}=125)\end{array}$ & $\%$ & $\begin{array}{l}\text { Post-test } \\
(\mathrm{N}=123)\end{array}$ & $\%$ \\
\hline \multicolumn{5}{|l|}{ Piaget } \\
\hline - Piaget Sensorimotor Stage & 73 & 58.4 & 81 & 65.9 \\
\hline - Concrete Operational Thought & 68 & 54.4 & 59 & 48.0 \\
\hline - $\quad$ Piaget’s Cognitive Development & 97 & 77.6 & 104 & 84.6 \\
\hline - Object Permanence & 116 & 92.8 & 116 & 94.3 \\
\hline - Centration & 48 & 38.4 & 57 & 46.3 \\
\hline - Piaget's Symbolic Thought & 24 & 19.2 & 23 & 18.7 \\
\hline - Imaginary Audience & 10 & 8.0 & 20 & 16.3 \\
\hline - Egocentrism & 91 & 72.8 & 107 & 87.0 \\
\hline - $\quad$ Magical Thinking & 106 & 84.8 & 111 & 91.2 \\
\hline - $\quad$ Piaget's Stages - Preoperational & 89 & 71.2 & 93 & 75.6 \\
\hline & 69 & 55.2 & 78 & 63.4 \\
\hline - Animism & 113 & 90.4 & 120 & 97.6 \\
\hline \multicolumn{5}{|l|}{ Erikson } \\
\hline - $\quad$ Negativism & 110 & 88.0 & 115 & 93.5 \\
\hline - Erikson’s Adolescent Crisis & 104 & 83.2 & 103 & 83.7 \\
\hline - Pre-school children and sense of guilt & 61 & 48.8 & 76 & 61.8 \\
\hline - Autonomy versus Shame and Doubt Crisis & 15 & 12.0 & 12 & 9.76 \\
\hline - $\quad$ Erikson’s first Stage (Trust) & 72 & 57.6 & 64 & 52.0 \\
\hline - Erikson Industry vs. Inferiority & 95 & 76.0 & 117 & 95.1 \\
\hline - Identity & 115 & 92.0 & 113 & 91.9 \\
\hline \multicolumn{5}{|l|}{ Physical } \\
\hline - Preschoolers Fine Motor Skills & 89 & 71.2 & 100 & 81.3 \\
\hline - Rate of Growth 7-11 year olds & 74 & 59.2 & 78 & 63.4 \\
\hline - Characteristics of Adolescents & 90 & 72.0 & 98 & 79.7 \\
\hline - Proximodistal Development & 6 & 4.8 & 112 & 91.1 \\
\hline - Myelinization & 99 & 79.2 & 102 & 82.9 \\
\hline - Moro Reflex & 99 & 79.2 & 104 & 84.6 \\
\hline - Infant Developmental Milestone - Sitting & 9 & 7.2 & 14 & 11.4 \\
\hline
\end{tabular}

Students had knowledge deficits regarding main concepts related to Piaget Cognitive development theory. More than $50 \%$ did not know what concrete and preoperational thought is, $83 \%$ did not know what personal fable is after finishing their courses. Almost 50\% did not know the infants' developmental task according to Erikson Psychosocial theory and more than $40 \%$ did not know the preschooler developmental task at the end of the semester. There was little improvement in students’ psychosocial development knowledge $(t=2.23, p=.027)$.

\section{Discussions}

A sound knowledge of growth and development is critical in providing optimal and comprehensive care for child and family. It is also essential in detecting any developmental delay. The purpose of this study was to assess senior nursing students' knowledge about normal child growth and development before and after Pediatric nursing didactic and clinical courses. Finding of this study revealed weak mean knowledge scores even in the posttest after completing didactic and clinical practice. This finding is congruent with other study for medical students. Health care provider had insufficient knowledge about early childhood development and behavior ${ }^{[9]}$. 
There was a significant difference in the student mean score between pre/posttest, however, students failed to achieve the achievement level of $80 \%$ at the end of the semester. Although no previous studies tested nursing students' knowledge about child growth and development, this finding is supported by other researcher who tested Pediatric nurses' knowledge of growth and development principles ${ }^{[4]}$. In her study nurses mean knowledge score was 27out of 35, which is a little higher compared to our students posttest scores 19 out of 28. These findings highlight the importance of innovative teaching strategies for teaching child growth and development in didactic courses and clinical settings such as case studies and scenarios with age appropriate developmental anticipatory guidance, developmental screening clinical day, and use of web-based modules to illustrate the main developmental milestones and concepts of developmental theories. An understanding of the principles of development will help student to plan appropriate activities that are stimulating and enriching experiences for children, and provides a basis for understanding how to encourage and support young children's engagement in their care.

The results of this study, however, must be considered in the context of its limitations, this study was conducted in one program, which limit the chance of generalization of the findings as each program has its strength and weakness. Although we have considered the content validity of the questionnaire, the internal consistency results was low. In addition, the questionnaire focused more on Piaget Cognitive development and Erikson Psychosocial developmental theories. Despite these limitations, this study is the first study to document nursing students' knowledge about growth and development and to highlight the need for teaching strategies that facilitate child growth and development knowledge transfer and application.

\section{Conclusions and recommendation}

Knowledge of growth and development is essential in all clinical settings that students' nurses will practice in such as primary care settings, acute care, or emergency care department. Findings of this study revealed students' knowledge deficit of normal child growth and development after completing their pediatric courses. These results address important issue to nursing education. Using online interactive modules and videos, using standardized developmental assessment guide, and using standardized assessment tools such as Ages and Stages Questionnaire may improve students and care providers' retention of knowledge of child development and behavior and guide their assessment process ${ }^{[10-13]}$. Studies found these strategies effective in improving knowledge, self-confidence to conduct developmental assessment and improved students’ perception about parental involvement in their child developmental assessment.

\section{I mplications to nursing education}

Results of this study provides important insight to nursing education to find strategies to improve child growth and development teaching and use multi-strategies to ensure application of the growth and development knowledge into clinical practice. Creative strategies that improve students' growth and development knowledge retention and transfer such as case studies and scenarios that clarify the main concepts of the main developmental theories are warranted. More structured clinical experience to help students relate theoretical knowledge to practice such as developmental screening Day. Importance of focusing on the basic developmental theories concepts to be able to provide developmentally appropriate care.

\section{References}

[1] Hockenberry, M. \& Wilson, D. Wong's Nursing Care of Infants and Children, 9th ed., St. Louis, Missouri, Elsevier, Mosby, 2011.

[2] American Association of College of Nursing. The essentials of baccalaureate education for professional nursing practice [Internet]. Available from: http://www.aacn.nche.edu/Education/pdf/BaccEssentials08.pdf. Retrieved February 28th, 2012. 
[3] Wendt, Kenny, \& Schultz, 2010 NCLEX-RN Detailed Test Plan for Candidates, National Council of State Boards of Nursing (NCBSN) [Internet]. Available from: https://www.ncsbn.org/2010_NCLEX_RN_Detailed_Test_Plan_Candidate.pdf. Retrieved February 2012.

[4] Gillis, A. J. Nurses' knowledge of growth and development principles in meeting psychosocial needs of hospitalized children. Journal of Pediatric Nursing. 1990; 5(2): 78-87.

[5] Ertem, I. O., Pekcici, E., Gok, C., Ozbas, S., Ozcebe, H., \& Beyazova, U. Addressing early childhood development in primary health care: experience from Middle-income country. Journal of Developmental Behavioral Pediatrics. 2009; 30: 319-326.

[6] Epp, Sh., \& McAulay, J. Teaching child growth and development, the Christmas shoebox. 2008; 33(6): 277-289.

[7] McDowell, B. Using toy critiques to teach growth and development. Nurse Educator. 2002; 27(5): 199-200. PMid:12355040 http://dx.doi.org/10.1097/00006223-200209000-00002

[8] Anderson, L.W., \& Krathwohl (Eds.). A Taxonomy for Learning, Teaching, and Assessing: A Revision of Bloom's Taxonomy of Educational Objectives. New York: Longman. 2001.

[9] Lian, W.B., Ho, S. K., Yeo, c. l. \& Ho, L. y. General practitioner' knowledge on childhood developmental and behavioral disorders, Singapore Medical Journal. 2003; 44(3): 227-230.

[10] Parkin, A. \& Dogra, N. Making video for medical undergraduate teaching in child psychiatry: the development, use and perceived effective ness of structured videotapes of clinical material for use by medical students in child psychiatry, Medical Teacher. 2000; 22(6): 568-571. PMid:21275691 http://dx.doi.org/10.1080/01421590050175541

[11] Ertem, I., Dogan, D., Dok, C. et al. A guide for monitoring child development in low and middle-income countries, Pediatrics. 2008; 212(3): e581-e589.

[12] Nicol, P. Using the Ages and Stages Questionnaire to teach medical students developmental assessment: a descriptive analysis, BMC Medical Education. 2006; 6: 29. PMid:16716208 http://dx.doi.org/10.1186/1472-6920-6-29

[13] Glasser, A., Nathan, D. \& Blair, M. Childhood developmental examination: A novel approach to teaching, Medical Education. 1997; 31: 272-275. PMid:9488842 http://dx.doi.org/10.1111/j.1365-2923.1997.tb02924.x 